\title{
Adaptasi Budaya, Alih Bahasa Indonesia, dan Validasi Sino-Nasal Outcome Test (SNOT)-22
}

\author{
Ichsan Juliansyah Juanda, Teti Madiadipoera, Sinta Sari Ratunanda \\ Departemen Ilmu Kesehatan Telinga Hidung Tenggorok Bedah Kepala Leher \\ Fakultas Kedokteran Universitas Padjadjaran/Rumah Sakit Dr. Hasan Sadikin Bandung
}

\begin{abstract}
Abstrak
Kuesioner untuk menilai kualitas hidup saat ini semakin meningkat penggunaannya dalam penelitian klinis hasil intervensi medis, baik operatif maupun medikamentosa. SNOT-22 dianggap sebagai alat ukur yang paling sesuai untuk menilai kualitas hidup pasien rinosinusitis kronik.Tujuan penelitian ini melakukan adaptasi budaya, alih bahasa, dan validasi SNOT-22 ke dalam bahasa Indonesia. Penelitian deskriptif analitik potong lintang pada 50 pasien rinosinusitis kronik di Poliklinik Rinologi Alergi Departemen Ilmu Kesehatan Telinga Hidung dan Tenggorok Bedah Kepala dan Leher (THT-KL) Fakultas Kedokteran Universitas Padjadjaran/Rumah Sakit Dr. Hasan Sadikin Bandung periode November 2015-Februari 2016. Diagnosis berdasar atas anamnesis, tingkat berat penyakit, nasoendoskopi berdasa Lund-Kennedy, dan penilaian kualitas hidup dengan SNOT-22. Validasi kuesioner dalam bahasa Indonesia dilakukan dengan menerjemahkan kuesioner SNOT-22 versi bahasa Inggris ke bahasa Indonesia oleh ahli bahasa Indonesia dan diterjemahkan kembali ke bahasa Inggris oleh ahli bahasa Inggris. Dilakukan uji reabilitas menggunakan Cronbach's alpha dan uji validitas menggunakan Rank Spearman's. Uji Cronbach's alpha $=0,936$ (sangat andal), andal jika $\geq 0,7$ menunjukkan konsistensi yang baik. Uji Rank Spearman's: $\mathrm{r}_{\mathrm{s}}=0,961$ dan $r_{s}=0,978$ (valid); dan keandalan (korelasi skor genap dengan skor ganjil) $r_{s}=0,900$. Simpulan, hasil uji statistik menunjukkan bahwa kuesioner SNOT-22 versi bahasa Indonesia merupakan alat ukur yang valid dengan konsistensi yang baik untuk menilai kualitas hidup pasien dengan rinosinusitis kronik. [MKB. 2017;49(4):267-73]
\end{abstract}

Kata kunci: Bahasa Indonesia, kualitas hidup, rinosinusitis kronik, SNOT-22, validasi

\section{Indonesian Cross-cultural Adaptation, Translation, and Validation of Sino-Nasal Outcome Test (SNOT)-22}

\begin{abstract}
Questionnaires for quality of life (QoL) have been increasingly used in clinical trials to evaluate the impact of medical and surgical procedures. Among these, SNOT-22 was considered as the most suitable tool for assessing QoL in chronic rhinosinusitis. The purpose of this study was to conduct cross-cultural adaptation, translation, and validation of the Indonesian version of SNOT-22. This was a descriptive analitical cross-sectional study on 50 patients with chronic rhinosinusitis at the Rhinology-Allergy Clinic of the ORL-HNS Department, Faculty of Medicine Universitas Padjadjaran/Dr. Hasan Sadikin General Hospital Bandung, during the period of November 2015-February 2016. Diagnosis was made based on anamnesis while the severity of the disease was determined using nasoendoscopic findings (Lund-Kennedy). QoL was measured using SNOT-22. The validation process of the Indonesian questionnaire included translation of original SNOT-22 in to Indonesian by independent Indonesian translators, and backtranslation to English by English translators. The reliability of the questionnaire was measured using Cronbach's alpha and the discriminant validity was assessed using Rank Spearman's. Results showed a Cronbach's alpha of 0,936, suggesting good internal consistency while the Rank Spearman's correlation results suggested that the translation was valid ( $r s=0.961$ and $r s=0.978$ ). Correlation for each individual QoL itemwas also reliable ( $\mathrm{rs}=0.900$ ). Therefore, the Indonesian version of the SNOT-22 is a valid instrument with good internal consistency and validity for assessing QoL in patients with CRS. [MKB. 2017;49(4):267-73]
\end{abstract}

Key words: Chronic rhinosinusitis, Indonesian, quality of life, SNOT-2, validation

Korespondensi: Ichsan Juliansyah Juanda, dr., Departemen Ilmu Kesehatan THT-KL Fakultas Kedokteran Universitas Padjadjaran/Rumah Sakit Dr. Hasan Sadikin, Jalan Pasteur No. 38 Bandung, E-mail: ichsanjuliansyah@gmail.com 


\section{Pendahuluan}

Rinosinusitis kronik merupakan suatu penyakit dengan insidensi dan prevalensi tinggi yang semakin meningkat sehingga menjadi beban perekonomian masyarakat. Rinosinusitis kronik (RSK) merupakan inflamasi mukosa hidung dan juga sinus paranasal dengan jangka waktu gejala $\geq 12$ minggu tanpa resolusi komplet dari gejala dan tanda akut ditandai oleh $\geq 2$ gejala yang salah satunya adalah hidung tersumbat atau sekret hidung (anterior, posteriornasal drip). ${ }^{1}$ Kondisi ini dapat disertai nyeri wajah spontan, atau menurunnya sensasi penghidu serta hasil temuan nasoendoskopi berupa sekret mukopurulen atau polip yang berasal dari meatus media dan atau obstruksi mukosa pada meatus media, dan/atau hasil dari computed tomography (CT) scan berupa perubahan mukosa pada kompleks osteomeatal dan atau sinus paranasal. ${ }^{2}$

Rinosinusitis kronik menjangkiti kurang lebih $10,9 \%$ populasi dewasa di Eropa ${ }^{1}$ dan $15 \%$ di USA. ${ }^{2}$ Didapatkan perbedaan secara geografi (7-27\%). Data di Subbagian Rinologi-Alergi Departemen Ilmu Kesehatan Telinga Hidung dan Tenggorok Bedah Kepala dan Leher (THT-KL) Fakultas Kedokteran Universitas Padjadjaran/ Rumah Sakit Dr. Hasan Sadikin (RSHS) pada tahun 2011 tercatat 45\% kasus rinosinusitis dari seluruh kasus di Poliklinik Rinologi Alergi, terdiri atas $46,04 \%$ laki-laki dan 53,86\% perempuan. Prevalensi rinosinusitis kronik lebih banyak pada perempuan dibanding dengan laki-laki dengan perbandingannya adalah $6: 4 .{ }^{1,2}$

Rinosinusitis kronik merupakan penyakit yang multifaktor dan memberikan dampak yang sangat signifikan terhadap kualitas hidup ${ }^{3}$ dan memengaruhi kondisi ekonomi. Disebutkan juga rinosinusitis kronik telah mengakibatkan 13 juta konsultasi kesehatan, 2 juta kunjungan ke UGD, dan 73 juta hari yang mengakibatkan seorang pekerja tidak masuk kerja di USA. ${ }^{4}$ Penyakit ini juga mengakibatkan banyaknya konsumsi obatobatan, tindakan operasi, dan rawat inap. Karena penyakit ini memberikan prevalensi yang tinggi dan dampak yang besar dalam hal ekonomi serta kualitas hidup, perlu dibuat alat ukur yang dapat menilai secara spesifik kualitas hidup pasien dengan rinosinusitis kronik. Selain itu, hal yang penting adalah kuesioner yang spesifik dapat membantu diagnosis dan penatalaksanaan terapi pada pasien. ${ }^{5}$

Dalam hal ini, Dr. Jay Piccirilo dari Universitas Washington d St. Louis, Missouri telah membuat Sino-Nasal Outcome Test-20 pada tahun 1998. ${ }^{6}$ Kuesioner ini digunakan untuk menilai kualitas hidup secara spesifik pada penderita rinosinusitis kronik dan telah banyak digunakan dalam berbagai penelitian ilmiah. ${ }^{7}$ Kuesioner ini merupakan kuesioner yang diisi sendiri oleh pasien dan terdiri atas 20 pertanyaan yang berhubungan dengan beberapa gejala, dengan jawaban bervasiasi mulai 0 hingga 5 bergantung pada beratnya gejala (nilai 5 merupakan jawaban untuk gejala kriteria derajat gangguan terhadap tiap domain, yaitu tanpa masalah dengan nilai 0 , masalah sangat ringan dengan nilai 1 , masalah ringan dengan nilai 2 , masalah-sedang dengan nilai 3, masalah parah dengan nilai 4 , masalah sangat parah dengan nilai 5 mencakup keluhan mulai 2 minggu sebelum dilakukan wawancara. Nilai total didapatkan dengan menjumlahkan seluruh nilai jawaban; jumlah nilai tertinggi memperlihatkan kualitas hidup yang menurun. ${ }^{6}$

Rinosinusitis adalah salah satu komorbiditas dari rinitis alergi, inflamasi, dan obstruksi ostium sinus yang terjadi karena diperantarai oleh IgE. Inflamasi kronik dapat menyebabkan sumbatan pada ostium sinus, perubahan mekanisme transpor mukosilier, dan stasis mukus. Gejala lain berupa obstruksi hidung yang diakibatkan oleh degranulasi sel mast dan basofil yang diperantarai IgE sehingga terjadi pelepasan mediator inflamasi. Pasien dengan rinosinusitis kronik mengalami gangguan tidur. Gangguan tidur pada pasien rinosinusitis kronik diawali dengan sumbatan hidung kemudian mendengkur hingga menjadi gangguan napas saat tidur dan henti nafas saat tidur. ${ }^{7}$

Beberapa mediator yang berperan dalam rinosinusitis kronik alergi juga memiliki peranan dalam patofisiologi gangguan tidur, yaitu histamin, IL-1, IL-4, IL-6, IL- 10, TNF- $\alpha$, PGD2, dan bradikinin. Di antara sitokin-sitokin tersebut yang menunjukkan peranan yang dominan dalam regulasi tidur adalah interleukin-1 (IL-1), interleukin-6 (IL-6), dan tumor necrosis factor- $\alpha$ (TNF- $\alpha)^{7,8}$

Pada saat ini secara luas telah digunakan beberapa kuesioner untuk menilai kualitas hidup pasien yang menderita penyakit kronik seperti SF-26, WPAI, WHO QoL, namun tidak spesifik. Dalam perkembangannya saat ini kuesioner yang spesifik menilai kualitas hidup pasien dengan rinosinusitis adalah Sinonasal Outcome Test-22 (SNOT-22) yang diperkenalkan tahun 2003 dan dibuat juga oleh Dr. Jay Piccirilo yang merupakan modifikasi dari SNOT-20 dengan penambahan 2 pertanyaan, yaitu sumbatan hidung dan perubahan dalam penghidu/perasa. Kedua gejala ini merupakan bagian dari kriteria diagnostik rinosinusitis kronik. ${ }^{9}$ Gejala sumbatan 
hidung merupakan gejala yang paling sering dikeluhkan kepada dokter spesialis THT-KL, dan gangguan penghidu merupakan gejala yang paling sering tidak membaik setelah dilakukan tindakan operasi. Perubahan pada kuesioner ini telah memberikan kontribusi yang baik dalam penilaian kualitas hidup pasien dengan rinosinusitis kronik.

Pertanyaan pada SNOT-22 dapat dibagi menjadi 4 ranah: 1 . gejala hidung; 2 . gejala wajah/telinga; 3 . gangguan tidur; 4. perubahan psikologis yang dapat memudahkan penilaian terhadap 4 bagian tersebut. Pada tahun 2009 di Inggris, The National Comparative Audit of Surgery for Nasal Polyposis and Chronic Rhinosinusitis melakukan validasi Sino-Nasal Outcome Test-22 dalam versi bahasa Inggris dan telah digunakan dalam penelitian evaluasi perbaikan pascaoperasi. Saat ini Sino-Nasal Outcome Test-22 merupakan kuesioner spesifik terbaik untuk menilai kualitas hidup pasien rinosinusitis kronik. ${ }^{10}$

Sino-Nasal Outcome Test-22 tersebut telah dialihbahasakan dan divalidasi di beberapa negara seperti Cina, Republik Ceko, Denmark, Lithuania, Iran, Yunani, Perancis, dan Portugal. ${ }^{11}$ Belum terdapat alih bahasa dan adaptasi budaya yang divalidasi ke dalam bahasa Indonesia menjadi dasar penelitian ini. Tujuan penelitian ini adalah mengalihbahasakan, mengadaptasi, dan memvalidasi Sino-Nasal Outcome Test-22 untuk digunakan di Indonesia.

\section{Metode}

Penelitian ini ialah penelitian deskriptif analitik potong lintang terhadap 50 orang pasien yang didiagnosis rinosinusitis kronik di Poliklinik Rinologi-Alergi Departemen Ilmu Kesehatan THT-KL Fakultas Kedokteran Universitas Padjadjaran/Rumah Sakit Dr. Hasan Sadikin Bandung periode November 2015-Februari 2016 untuk menilai validasi dari kuesioner SNOT-22 yang sudah diadaptasi ke bahasa Indonesia.

Validasi kuesioner versi bahasa Indonesia ini dilakukan dengan cara menerjemahkan kuesioner versi asli SNOT-22 dari bahasa Inggris ke bahasa Indonesia oleh ahli bahasa Indonesia dan diterjemahkan kembali ke bahasa Inggris oleh ahli bahasa Inggris. SNOT-22 dalam versi bahasa Indonesia. Kriteriainklusi pada penelitian ini hanya pasien dewasa usia 18-60 tahun yang menderita rinosinusitis kronik yang didiagnosis berdasar atas hasil anamnesis, pemeriksaan fisis diagnostik THT, serta dapat membaca dan menulis dengan baik. Kriteria eksklusi pada penelitian ini adalah usia di bawah 18 tahun, pasien yang tidak dapat membaca, pasien yang tidak sehat secara mental, dan wanita hamil.

Penilaian kualitas hidup pasien RSK dilakukan dengan mengisi kuesioner SNOT-22 versi bahasa Indonesia. Pengisian kuesioner dilakukan sendiri oleh pasien sambil didampingi oleh peneliti agar pasien dapat menanyakan hal-hal yang tidak dimengerti selama pengisian kuesioner. Hasil pengisian kuesioner kemudian dikumpulkan dan direkap datanya yang selanjutnya dinilai validitas dan reliabilitasnya secara statistik.

Diagnosis RSK dilakukan berdasar atas kriteria EPOS berupa rinore, hidung tersumbat, nyeri/rasa tertekan di wajah, dan gangguan penghidu. Penggunaan visual analog scale (VAS) telah terbukti relevan secara klinis dalam mengukur tingkat berat tiap gejala subjektif yang dirasakan pasien. Untuk menilai kondisi hidung pasien dilakukan dengan metode LundKennedy. ${ }^{1,12}$

Analisis statistik dilakukan menggunakan SPSS 15.0 for windows. Pemakluman (informed consent) didapat dari semua partisipan yang masuk kriteria inklusi pada studi ini. Para penulis mendeklarasikan bahwa tidak terdapat konflik kepentingan.

\section{Hasil}

Dalam penelitian ini didapatkan 50 pasien rinosinusitis kronik terdiri atas 23 orang lakilaki dan 27 orang perempuan. Distribusi subjek

\section{Tabel 1 Karakteristik Subjek}

\begin{tabular}{lc}
\hline \multicolumn{1}{c}{ Karakteristik } & Kelompok Penelitian \\
\hline Jenis kelamin & \\
Laki-laki & 23 \\
Perempuan & 27 \\
Usia (tahun) & \\
$18-20$ & $2(4 \%)$ \\
$20-29$ & $38(76 \%)$ \\
$30-39$ & $5(10 \%)$ \\
$40-45$ & $5(10 \%)$ \\
Rata-rata (SD) & 27,8 \\
Median & $(6,55)$ \\
Rentang & 27 \\
& $21-44$ \\
\hline
\end{tabular}


Tabel 2 Uji Keandalan Cronbach Alpha

\begin{tabular}{|c|c|c|c|c|c|}
\hline Pertanyaan & $\mathbf{N}$ & Minimal & Maksimal & Rata-rata & $\begin{array}{c}\text { Simpang } \\
\text { Baku }\end{array}$ \\
\hline Perlu menghembuskan hidung & 50 & 0 & 5 & 1,96 & 1,384 \\
\hline Hidung tersumbat & 50 & 0 & 5 & 2,56 & 1,631 \\
\hline Bersin-bersin & 50 & 0 & 5 & 1,86 & 1,262 \\
\hline Hidung berair/meler & 50 & 0 & 5 & 1,74 & 1,509 \\
\hline Keluhan batuk & 50 & 0 & 4 & 1,50 & 1,249 \\
\hline Produksi cairan hidung bagian belakang & 50 & 0 & 5 & 1,30 & 1,389 \\
\hline Cairan hidung yang kental & 50 & 0 & 5 & 1,24 & 1,546 \\
\hline Rasa penuh pada telinga & 50 & 0 & 5 & 0,96 & 1,125 \\
\hline Pusing & 50 & 0 & 5 & 1,54 & 1,487 \\
\hline Nyeri telinga & 50 & 0 & 5 & 0,98 & 1,229 \\
\hline Nyeri/tekanan di wajah & 50 & 0 & 5 & 1,56 & 1,716 \\
\hline $\begin{array}{l}\text { Berkurangnya indera penghidu/ } \\
\text { pengecap }\end{array}$ & 50 & 0 & 5 & 1,32 & 1,571 \\
\hline Sulit memulai tidur & 50 & 0 & 5 & 1,16 & 1,490 \\
\hline Terbangun malam hari & 50 & 0 & 5 & 0,96 & 1,442 \\
\hline Kurang tidur malam yang berkualitas & 50 & 0 & 5 & 1,04 & 1,456 \\
\hline Terbangun lelah & 50 & 0 & 5 & 1,06 & 1,376 \\
\hline Kelelahan sepanjang hari & 50 & 0 & 4 & 0,88 & 1,304 \\
\hline Penurunan produktivitas & 50 & 0 & 5 & 1,18 & 1,424 \\
\hline Penurunan konsentrasi & 50 & 0 & 5 & 1,16 & 1,517 \\
\hline Frustrasi/mudah marah & 50 & 0 & 5 & 1,02 & 1,491 \\
\hline Sedih & 50 & 0 & 4 & 0,77 & 1,216 \\
\hline Malu & 50 & 0 & 4 & 0,76 & ,938 \\
\hline Nilai total & 50 & 3 & 82 & 27.70 & 20.261 \\
\hline $\mathrm{N}$ Valid & 50 & & & & \\
\hline
\end{tabular}

Keterangan: hasil uji keandalan diperoleh Cronbach alpha = 0,936 (sangat andal: andal jika Cronbach alpha $\geq 0,7$ )

berdasar atas usia didapatkan usia 18-20 tahun berjumlah 2 orang (4\%), usia 20-29 tahun berjumlah 38 orang (76\%), usia 30-39 tahun berjumlah 5 orang (10\%) dan usia 40-45 tahun berjumlah 5 orang (10\%) (Tabel 1).
Dalam menilai keandalan, didapatkan hasil konsistensi internal yang baik dengan koefisien Cronbach alpha umum mencapai 0,936 yang menunjukkan homogenitas yang baik pada komponen berbeda (Tabel 2).

Tabel 3 Uji Validitas Rank Spearman

\begin{tabular}{|c|c|c|c|c|}
\hline \multicolumn{2}{|c|}{ Rank Spearman } & \multirow{2}{*}{$\begin{array}{c}\text { Nilai Total } \\
1,000\end{array}$} & \multirow{2}{*}{$\begin{array}{c}\text { Nilai Genap } \\
0,961^{* *}\end{array}$} & \multirow{2}{*}{$\frac{\text { Nilai Ganjil }}{0,978^{* *}}$} \\
\hline Nilai_total & Koefisien korelasi & & & \\
\hline & Sig. (2-tailed) & & ,000 & 0,000 \\
\hline & $\mathrm{N}$ & 50 & 50 & 50 \\
\hline \multirow[t]{3}{*}{ Nilai_genap } & Koefisien korelasi & $0,961^{* *}$ & 1,000 & $0,900 * *$ \\
\hline & Sig. (2-tailed) & 0,000 & & ,000 \\
\hline & $\mathrm{N}$ & 50 & 50 & 50 \\
\hline \multirow[t]{3}{*}{ Nilai_ganjil } & Koefisien korelasi & $0,978^{* *}$ & $0,900 * *$ & 1,000 \\
\hline & Sig. (2-tailed) & 0,000 & 0,000 & \\
\hline & $\mathrm{N}$ & 50 & 50 & 50 \\
\hline
\end{tabular}

Keterangan: hasil uji validitas, yaitu dengan mengorelasikan skor butir genap dengan total skor dan skor ganjil dengan total skor diperoleh berturut-turut: $r_{s}=0,961$ dan $r_{s}=0,978$ (valid: $r \geq 0,7$ ); dan andal (korelasi skor genap dengan skor ganjil $r_{s}=0,900$ (andal) 
Dari hasil penelitian dilakukan uji validitas Rank Spearman dengan mengorelasikan skor pertanyaan genap dengan total skor dan skor pertanyaan ganjil dengan total skor diperoleh berturut-turut: $r_{s}=0,961$ dan $r_{s}=0,978(r \geq 0,7)$ dan hasil yang andal (korelasi skor genap dengan skor ganjil $r_{s}=0,900$ (Tabel 3).

\section{Pembahasan}

Berdasar atas EPOS pada tahun 2012 prevalensi rinosinusitis kronik tanpa polip hidung lebih tinggi pada wanita apabila dibanding dengan pada pria dengan rasio 6:4. Penelitian lain di Kanada memperlihatkan rentang prevalensi sekitar $3,4 \%$ pada pria dan $5,7 \%$ pada wanita. Prevalensi ini semakin meningkat sejalan dengan bertambahnya usia, dengan rata-rata $2,7 \%$ dan 6,6\% pada usia kelompok 20-29 dan 50-59 tahun. ${ }^{1}$ Penelitian di Korea menunjukkan tidak ada perbedaan prevalensi rinosinusitis kronik tanpa polip hidung antara pria dan wanita. Pada penelitian ini ditemukan prevalensi rinosinusitis kronik tanpa polip laki-laki dibanding dengan wanita, tidak berbeda dengan rasio $1: 1 .^{2} \mathrm{Hal}$ ini

\section{Tabel 4 Alih Bahasa Kuesioner SNOT-22 ke Bahasa Indonesia}

SNOT-22. Di bawah ini Anda akan menemukan daftar gejala dan konsekuensi sosial/emosional dari rinosinusitis Anda. Kami ingin mengetahui lebih banyak mengenai masalah ini dan akan sangat menghargai jawaban dari pertanyaan-pertanyaan berikut ini sebaik Anda bisa. Tidak ada jawaban benar atau salah dan Anda hanya perlu memberikan kami informasi berikut ini. Mohon beri penilaian mengenai masalah yang Anda alami dalam dua minggu terakhir. Terima kasih untuk partisipasi Anda. Jangan ragu untuk meminta bantuan bila diperlukan.

\begin{tabular}{|c|c|c|c|c|c|c|c|}
\hline $\begin{array}{l}\text { 1. Mempertimbangkan betapa parahnya } \\
\text { masalah ketika Anda mengalami dan } \\
\text { berapa sering hal itu terjadi. Mohon } \\
\text { berikan nilai setiap komponen di bawah } \\
\text { ini mengenai betapa "buruk"-nya } \\
\text { komponen tersebut dengan melingkari } \\
\text { nomor yang sesuai dengan perasaan } \\
\text { Anda menggunakan skala berikut ini: }\end{array}$ & 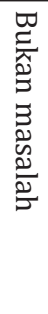 & 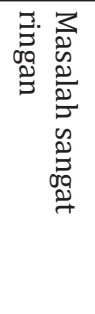 & 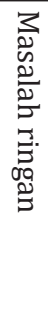 & $\begin{array}{l}3 \\
3 \\
0 \\
0 \\
0 \\
0 \\
0 \\
0 \\
0 \\
0 \\
0 \\
0 \\
0 \\
09\end{array}$ & 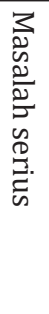 & 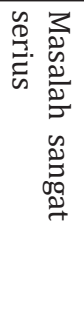 & 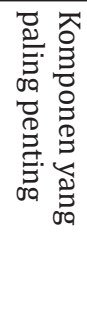 \\
\hline Perlu menghembuskan hidung & 0 & 1 & 2 & 3 & 4 & 5 & 0 \\
\hline Hidung tersumbat & 0 & 1 & 2 & 3 & 4 & 5 & 0 \\
\hline Bersin-bersin & 0 & 1 & 2 & 3 & 4 & 5 & 0 \\
\hline Hidung berair/meler & 0 & 1 & 2 & 3 & 4 & 5 & 0 \\
\hline Keluhan batuk & 0 & 1 & 2 & 3 & 4 & 5 & 0 \\
\hline Produksi cairan hidung bagian belakang & 0 & 1 & 2 & 3 & 4 & 5 & 0 \\
\hline Cairan hidung yang kental & 0 & 1 & 2 & 3 & 4 & 5 & 0 \\
\hline Rasa penuh pada telinga & 0 & 1 & 2 & 3 & 4 & 5 & 0 \\
\hline Pusing & 0 & 1 & 2 & 3 & 4 & 5 & 0 \\
\hline Nyeri telinga & 0 & 1 & 2 & 3 & 4 & 5 & 0 \\
\hline Nyeri/ tekanan di wajah & 0 & 1 & 2 & 3 & 4 & 5 & 0 \\
\hline $\begin{array}{l}\text { Berkurangnya indera penghidu/ } \\
\text { pengecap }\end{array}$ & 0 & 1 & 2 & 3 & 4 & 5 & 0 \\
\hline Sulit memulai tidur & 0 & 1 & 2 & 3 & 4 & 5 & 0 \\
\hline Terbangun malam hari & 0 & 1 & 2 & 3 & 4 & 5 & 0 \\
\hline Kurang tidur malam yang berkualitas & 0 & 1 & 2 & 3 & 4 & 5 & 0 \\
\hline Terbangun lelah & 0 & 1 & 2 & 3 & 4 & 5 & 0 \\
\hline Kelelahan sepanjang hari & 0 & 1 & 2 & 3 & 4 & 5 & 0 \\
\hline Penurunan produktivitas & 0 & 1 & 2 & 3 & 4 & 5 & 0 \\
\hline Penurunan konsentrasi & 0 & 1 & 2 & 3 & 4 & 5 & 0 \\
\hline Frustrasi/mudah marah & 0 & 1 & 2 & 3 & 4 & 5 & 0 \\
\hline Sedih & 0 & 1 & 2 & 3 & 4 & 5 & 0 \\
\hline Malu & 0 & 1 & 2 & 3 & 4 & 5 & 0 \\
\hline
\end{tabular}

2. Mohon tandai komponen yang paling penting yang memengaruhi kesehatan Anda (maksimum 5) 
terjadi karena jumlah sampel penelitian hanya sedikit sehingga tidak dapat menggambarkan prevalensi secara umum.

Alih bahasa dan adaptasi kultural dari kuesioner merupakan sebuah proses kompleks yang melibatkan proses terjemah yang ekivalen secara konsep dengan teks asal dan secara kultural harus selalu dapat diterima di negara tujuan. Pada kasus ini, terjemahan kuesioner dilakukan melalui metode yang dideskripsikan pada literatur ilmiah dan diadopsi oleh beberapa penulis pada terjemahan kuesioner yang sama ke bahasa yang lain.

Untuk validasi yang tepat, kuesioner harus memenuhi hal kriteria validitas, reliabilitas, dan reproduksibilitas yang telah ditegakkan sebelumnya. Dari penelitian ini disimpulkan bahwa SNOT-22 pada versi bahasa Indonesia merupakan kuesioner yang mudah digunakan secara baik pada pasien dengan RSK. Sangatlah mudah untuk diimplementasikan oleh tenaga kesehatan profesional dan mempermudah peneliti dalam mendapatkan data statistik.

Pada evaluasi konsistensi internal (Tabel 1) didapatkan nilai Cronbach alpha adalah 0,936 yang serupa dengan penelitian yang sebelumnya dilaporkan oleh penulis lain (Piccirillo $=0,90^{14}$, Jalessi $=0,898^{11}$, Bauman $=0.87^{2}$, Hopkins $=$ $0.91^{10}$ ).

Simpulan, hingga saat ini belum terdapat kuesioner tervalidasi untuk dapat mengevaluasi kualitas hidup pada pasien rinosinusitis kronik di Indonesia. Terjemahan dan validasi dari SNOT22 di Indonesia memungkinkan penilaian yang lebih konsisten terhadap kualitas hidup pasien ini, begitu juga keefektifan dari penanganan medis dan operatif.

Oleh karena itu, kuesioner ini merupakan alat ukur yang berguna, dapat dipercaya, dan sangat penting, baik digunakan dalam praktik sehari-hari maupun dalam berbagai penelitian. Kuesioner ini memungkinkan didapatkan hasil yang baku dan dapat perbandingan dengan studi internasional.

\section{Daftar Pustaka}

1. Barros E, Silva A, Sousa Vieira A. Prevalance and characteristic of rhinosinusitis at primary health care in Portugal. Rev Port ORL. 2012;50(2):5-12.

2. Baumann I, Blumenstock G, DeMaddalena $\mathrm{H}$, Piccirillo JF, Plinkert PK. Quality of life in pasien with cronic rhinosinusitis: validation of the sino-nasal outcome test-20 German adapted version. HNO. 2007;55(1):42-7.

3. Blackwell DL, Lucas JW, Clarke TC. Summary health statistics for U.S. adults: national health interview survey. Vital Health Stat 10. 2014;(260):1-161.

4. Ciprandi G, Mora F, Cassano M, Gallina AM, Mora R. Visual analog scale (VAS) and nasal obstructionin persistent allergic rhinitis. Otolaryngol Head Neck Surg. 2009; 141(4):527-39.

5. Eccles R. Mechanisms of the symptoms of rhinosinusitis. Rhinology. 2011;49(2):131-8.

6. Ferguson BJ. Influence of allergic rhinitis on sleep. Otolaryngol Head Neck Surg. 2004; 130(5):617-29.

7. Fokkens WJ, Lund VJ, Mullol J, Bachert C, Alobid I, Baroody F, dkk. EPOS 2012: European position paper on rhinosinusitis and nasal polyps 2012. A summary for otorhinolaryngologists. Rhinology. 2012; 50(1):1-12.

8. Hamilos D. Chronic rhinosinusitis: epidemiology and medical management. J Allergy Clin Immunol. 2011;128(4):693707.

9. Hastan D1, Fokkens WJ, Bachert C, Newson RB, Bislimovska J, Bockelbrink A, dkk. Chronic rhinosinusitis in Europe-an underestimated disease. Allergy. 2011;66(9):1216-23.

10. Hopkins C, Gillett S, Slack R, Lund VJ, Browne JP. Psychometric validity of the 22-item sinonasal outcome test. Clin Otolaryngol. 2009;34(5):447-54.

11. Jalessi M, Farhadi M, Kamrava SK, Amintehran E, Asghari A, Rezaei Hemami M, dkk. The reliability and validity of the persian version of sinonasal outcome test 22 (SNOT-22) questionnaires. Iran Red Crescent Med J. 2013;15(5):404-8.

12. Kosugi EM, Chen VG, Fonseca VM, Cursino MM, Mendes Neto JA, dkk. Translation, cross-cultural adaptation and validation of sinonasal outcome test (SNOT): 22 to Brazilian Portuguese. Braz J Otorhinolaryngol. 2011;77(5):663-9.

13. Lund V, Kennedy D. Staging for rhinosinusitis. Otolaryngol Head Neck Surg. 1997;117(3 Pt 2):S35-40.

14. Piccirillo JF, Merritt MG Jr, Richards ML. Psychometricand clinimetric validity of the 20-item sino-nasal outcome test (SNOT-20). Otolaryngol Head Neck Surg. 2002;126(1): 41-7.

15. de Vilhena D, Duarte D, Lopes G. Sino-Nasal Outcome Test-22: translation, cultural adaptation and validation in Portugal. 
Ichsan Juliansyah Juanda: Adaptasi Budaya, Alih Bahasa Indonesia, dan Validasi Sino-Nasal Outcome Test (SNOT)-22

Otolaryngol. Clin Otolaryngol. 2016;41(1): 21-4.

16. Farhood Z, Schlosser RJ, Pearse ME, Storck KA, Nguyen SA, Soler ZM. Twenty-two- item Sino-Nasal Outcome Test in a control population: a cross-sectional study and systematic review. Int Forum Allergy Rhinol. 2016;6(3):271-7. 